\title{
Biomimetic Coating Technology for Orthopedic Implants
}

\author{
Naresh Koju ${ }^{\mathrm{a}}$, Prabaha Sikder ${ }^{\mathrm{a}}$, Yufu Ren ${ }^{\mathrm{a}}$, Huan Zhou ${ }^{\mathrm{c}}$, Sarit B. Bhaduri ${ }^{\mathrm{a}, \mathrm{b}^{*}}$ \\ ${ }^{a}$ Department of Mechanical Industrial and Manufacturing Engineering, \\ The University of Toledo, Toledo, $\mathrm{OH} 43606$, USA \\ ${ }^{b}$ Division of Dentistry, The University of Toledo, Toledo, $\mathrm{OH} 43606$, USA \\ ${ }^{c}$ Changzhou University, Changzhou, Jiangsu 213164, China
}

\begin{abstract}
Biomimetic coating process is one of the most versatile techniques developed for coating various orthopedic implant surfaces. The surface of an orthopedic implant, whether it is biodegradable or non-biodegradable, needs to be bioactive for osseointegration (direct bonding with bone). The above mentioned coating technique is employed to deposit a bone-like apatite (calcium phosphate) on the implant surfaces, so that the implants become more bioactive, resulting in osseointegration. Simulated body fluids (SBFs) play a critical role in this method. This short review describes and critiques the progresses made in this field by focusing on: 1) the compositional aspects of various SBFs; 2) the strategies to enhance the coating kinetics; and 3) examples of coating various types of surfaces of implants fabricated from polymers and metals, both biodegradable and non-biodegradable in nature.
\end{abstract}

Keywords: Biomimetic coating, Osseointegration, Apatite, SBF.

*Corresponding author: Tel.: +1 419252 0500;

E-mail address: sarit.bhaduri@gmail.com (Sarit B. Bhaduri)

(C) 2016. This manuscript version is made available under the Elsevier user license http://www.elsevier.com/open-access/userlicense/1.0/ 


\subsection{Introduction}

Coating of various orthopedic implant surfaces using the "Biomimetic Technique" has become a popular research topic over the last two decades. The technique is especially beneficial to produce bone-like calcium deficient carbonated hydroxyapatite (CDHA) coating on an implant surface so that it can osseointegrate (forming direct bond) with the adjacent bone at the implant site without being surrounded by any fibrous tissue. However, as noted below, there are other uses of the technique. An integral part of the technique is the use of "Simulated Body Fluid (SBF)". A literature search conducted in the Web of Science database using the key words "Biomimetic Coating Simulated Body Fluid" yielded results reported in the last two decades, as shown in Figures 1(a) and 1(b). Figure 1(a) shows the number of publications, while Figure 1(b) presents the number of citations for each year. It is very clear that prior to 2000, the topic was in a nascent stage but started to become popular after 2001-2002 as both the number of publications and citations started to increase. The data also reveal that the number of publications and citations peaked during 2013-2014. The h-factor for the topic is a respectable 56. In the opinion of the authors, the immense popularity of the technique is due to the seminal review paper by Kokubo, published in 1998 [1]. Kokubo also coined the term SBF. It is quite evident that the artificially created medium should behave like the fluids present in the body with the caveat that such compositions are devoid of any organic species such as proteins, amino acids etc. In some sense, words such as biomimicry and SBF are synonymous to each other. The main advantage of the method is due to its benign nature. This is in contrast to the high temperature processes such as plasma spray, which can degrade the underlying substrates being coated. While not posing a crucial problem for coating metals, high temperature processes are not 
suitable for coating low melting point polymers, which are being increasingly used in orthopedics including scaffolds in the regeneration of bone.

Very briefly, the process involves an initial surface preparation step involving alkali, acid or a heat treatment prior to soaking in the SBF during which several reactions take place, as detailed below and described in Figure 2. The soaking is performed at physiological conditions (at $37^{\circ} \mathrm{C}$ and solution $\mathrm{pH}$ of 7.4 with the help of buffers) typically for three weeks [2]. This is why the process can be classified as biomimetic. Heterogeneous nucleation and growth of bone-like CDHA takes place on the surface of implants [3-5]. Taking the specific example of titanium and related alloys, in the first step, the alkali pre-treatment forms a layer of amorphous sodium titanate on the Ti surface. In the second step, during SBF soaking, the sodium titanate layer results in the formation of Ti-OH groups on its surface. In the third step, the Ti-OH groups interact with the local calcium ions from the SBF to form a layer of amorphous calcium titanate. In the fourth step, the amorphous calcium titanate converts to amorphous calcium phosphate (ACP) with a $\mathrm{Ca} / \mathrm{P}$ ratio of approximately 1.4. In the final step, the ACP gets converted into bone-like $\mathrm{CDHA}$ with a $\mathrm{Ca} / \mathrm{P}$ ratio of approximately 1.65 , which was close to the value of bone mineral [2].

The purpose of this short review is to provide some new perspectives of this interesting coating process, which has relevance in the orthopedic implant market. As noted in the above, there are two important motivations. First, as noted in the above, the technique is approximately twenty years old and it has undergone some very interesting modifications. The authors feel that this is the appropriate time to review such developments. Accordingly, the topics of this short review will include: 1) development of various compositions of SBF; 2) acceleration of the coating kinetics; and 3) coating various substrates such as metallic and polymeric substrates. Second, in 
spite of all the publications in the literature, there is still no review available addressing the interesting issues presented in the above. Thus, this review can be considered timely.

\subsection{Composition development}

Table 1 provides the details of various SBF compositions. The motivation for the development of SBFs is derived from two well-known culture media: Earle's (EBSS) and Hanks' Balanced Salt Solution (HBSS) [6], which themselves are derivatives of physiological saline media developed by Ringer [6]. To ensure mimicking the composition of human plasma, buffers are used to maintain the physiological pH of 7.4. TRIS (tris-hydroxymethyl-aminomethane)- $\mathrm{HCl}$ [3] or HEPES (2 (4-(2-hydroxyethyl)-1-piperazinyl)ethane sulphonic acid)- $\mathrm{NaOH}[10,11]$ are the two commonly used buffers. Kokubo's original composition of SBF (also known as conventional- SBF or c-SBF) is actually derived from HBSS using TRIS/HCl as the buffer with a $\mathrm{Ca} / \mathrm{P}$ ratio increased to 2.5 . Both of the buffers have minor drawbacks. TRIS-buffer can produce soluble complexes with several cations, including $\mathrm{Ca}^{2+}$. This limits the concentration of free $\mathrm{Ca}^{2+}$ ions available for the real time calcium phosphate coating. Such a behavior is not known for HEPES. On the other hand, Dorozhkina et al. [12] reported that HEPES is unstable, in comparison to TRIS, and it easily loses some of the initially present dissolved carbonates. It is important that the compositions contain the correct amount of $\mathrm{HCO}_{3}{ }^{-}$at the level of $27 \mathrm{mM}$, thus mimicking the composition of the blood plasma. However, c-SBF composition being a derivative of HBSS, had the concentration of $\mathrm{HCO}_{3}{ }^{-}$at $4.2 \mathrm{mM}$ [1]. Tas et al. were the first to raise the carbonate ion concentration in a TRIS-HCl buffered SBF solution to $27 \mathrm{mM}[12,13]$, while Bigi et al. [10] were the first to do the same in a HEPES-NaOH buffered SBF solution. Oyane et al. [11], who developed the HEPES-buffered r-SBF recipe, also reported that $\mathrm{r}-\mathrm{SBF}$ would release $\mathrm{CO}_{2}$ gas from the fluid, causing a decrease in $\mathrm{HCO}_{3}{ }^{-}$concentration, and an increase in $\mathrm{pH}$ value, 
when the storage period was long.

\subsection{Acceleration of the coating kinetics}

The major problem with biomimetic coating using SBFs is the slow kinetics of coating deposition. In the literature, two strategies have been reported. Both of them rely on relaxing the stringent biomimetic conditions. In the first strategy, higher strength (than the usual ionic concentrations in the plasma) SBFs are employed. Solutions equal to 1.5 times the ionic concentration of SBF were often used [14-16]. While Sun and Wang [17] and Miyaji et al. [18] prepared 2X (two times stronger) solutions, Habibovic et al. [19] prepared 5X (five times stronger) SBF-like solutions, without using any buffering agents and also removing $\mathrm{K}^{+}$and $\mathrm{SO}_{2-4}$ ions from their solutions. Tas and Bhaduri [7] demonstrated the successful use of 10X SBF-like (i.e., $25 \mathrm{mM} \mathrm{Ca}^{2+}$ and $10 \mathrm{mM} \mathrm{HPO}_{2-4}$ ) solutions in coating Ti6A14V surfaces at room temperature within 2 to 6 hours. It is noted that condensed (e.g., 5 or 10 times) solutions similar to SBF are prone to form precipitates with a higher carbonate content or with off-stoichiometric $\mathrm{Ca} / \mathrm{P}$ molar ratios $[7,20]$.

In the second strategy, Bhaduri group has employed a microwave assisted strategy to accelerate the kinetics of formation $[8,9]$. In this case, the SBF is defined as "Supersaturated Biomimetic Fluids" with the connotation that by relaxing the stringent biomimetic conditions, the fluids are supersaturated with the relevant ions and yet do not exactly copy the composition of the ions in the plasma. The conventional and the microwave assisted processes are compared and contrasted in Figure 2. As noted before there are several stages of the coating process. In the first stage the sodium titanate forms on the $\mathrm{Ti}$ substrate. In the second stage, $\mathrm{Ti}-\mathrm{OH}$ groups are formed on the 
surface and these groups are responsible for calcium phosphate nucleation. In stages 3 and 4, there is further growth of the coating from the nascent nuclei. However, in the next stage there is a difference between the conventional process and the microwave assisted process. As indicated in the Figure 2, the surface of Ti6Al4V is completely coated with apatite coating composed of large Ca-P globules linked to each other. This results in a thick coating. In the microwave assisted process, two phenomena occur: 1) due to the increasing temperature of aqueous medium caused by microwave heating, the coating deposition rate is significantly accelerated (typically about five minutes); 2) instead of apatite coating expanding on the surface of Ti6Al4V, a large number of Ca-P nuclei is formed on the whole surface of Ti6Al4V.

Muller et al. [21] recorded that the addition of $\mathrm{NaN}_{3}$ inhibits the growth of bacteria in SBF solution. During 2 week soaking in SBF, a layer of nanosized plate forming spherical aggregates with diameter of up to $10 \mu \mathrm{m}$ was formed. The average $\mathrm{Ca} / \mathrm{P}$ molar ratio increased from 1.35 for SBF 5 to 1.46 with increase of $\mathrm{HCO}_{3}{ }^{-}$concentration. The equilibrium decomposition reaction in solution with higher $\mathrm{HCO}_{3}{ }^{-}$concentration is more prominent resulting higher $\mathrm{pH}$ value and thus cause a strong increase in supersaturation.

\subsection{Biomimetic coatings on polymer substrates}

Developing calcium phosphate layer on polymer substrates have gained considerable importance due to its enhanced biocompatibility. Biomimetic, spray coating, laser deposition, coupling, and low-temperature precipitation processes are some of the coating techniques employed. Among these, biomimetic coating is the most commonly used one. However, before coating is done, pretreatment of substrate is quite requisite for surface modification. Table 2 summarizes the biomimetic coatings formulated on the common polymer substrates. 


\subsection{Biomimetic coatings on metallic substrates}

Be it fabricating orthopedic or dental implants, appropriate metallic substrates find useful applications due to their intrinsic properties like high fracture toughness, favorable strength to weight ratio, good ductility, and biocompatibility. Titanium and related alloys are by far the most popular ones in fabricating implants. However, bioactivity of such materials can be enhanced both in-vitro and in-vivo by coating them with bone-like apatites. In order to enhance osseointegration, specific coating procedures like plasma-spray, sol-gel are employed on $\mathrm{Ti}$ substrate. Yet, such coating techniques offer disadvantages like non-uniformity in thickness, lack of adherence to substrate, high processing temperatures etc. Biomimetic route is one promising coating technique which addresses such issues related to Ti-based implants [41-44]. More recently, magnesium $(\mathrm{Mg})$ and related alloys have emerged as viable implant materials [48]. Combinations of properties like low Young's modulus, high strength/weight ratio, biodegradability as well as biocompatibility make them important in this field. Yet, their fast degradation restricts their practical applications. To date, many kinds of protective coatings such as calcium phosphate, polymeric films have been developed to tailor the degradation rate of magnesium alloy substrates, which would facilitate the alloys to maintain the mechanical integrity prior to the complete healing of fractured bones [49-54]. Table 3 summarizes some of the important biomimetic coating results on popular metallic substrates.

\subsection{Summary}

The motivation for writing this short review is essentially derived from the novelty of the biomimetic coating process. Indeed, from its initial version, the process has evolved to a great extent in terms of understanding the science as well as translatory significances. Not only are there various versions of compositions available, by relaxing the stringent biomimicking 
conditions, many more industrially viable developments have been accomplished. Specifically, rapid strides have been made in accelerating the kinetics of deposition and enlarging the varieties of substrates. However, due to shortage of space several other interesting aspects of the process were left out from this paper. We hope to include other aspects of the process in longer and expanded papers in future.

\section{Acknowledgement}

This work is supported by NSF grant 1312211 . 


\section{References}

1. Kokubo T. Apatite formation on surfaces of ceramics, metals, and polymers in body environment. Acta Mater 1998; 46:25190-2527.

2. Dorozhkin SV. Calcium orthophosphate coatings, films, and layers. Progress in Biomaterials 2012; 1:1-40.

3. Takadama H, Kim HM, Kokubo T, Nakamura T. TEM-EDX study of mechanism of bonelike apatite formation on bioactive titanium metal in simulated body fluid. $\mathrm{J}$ Biomed Mater Res 2001; 57:441-448.

4. Uchida M, Kim HM, Kokubo T, Fujibayashi S, Nakamura T. Structural dependence of apatite formation on titania gels in a simulated body fluid. J Biomed Mater Res A 2003; 64A:164-170.

5. Kokubo T, Yamaguchi S. Bioactive layer formation on metals and polymers. In: Ducheyne P, Healy K, Hutmacher DW, Grainger DW, Kirkpatrick CJ (eds) Comprehensive biomaterials, vol. 1. Elsevier, Amsterdam, Netherlands, 2011:231244.

6. *Jalota S, Bhaduri SB, Tas AC. Effect of carbonate content and buffer type on calcium phosphate formation in SBF solution. J Mater Sci-Mater M 2006; 17:697-707.

7. **Tas AC, Bhaduri SB. Rapid coating of Ti6A14V at room temperature with a calcium phosphate solution similar to 10x simulated body fluid. J Mater Res 2004; 
19:2742-2749.

8. **Zhou H, Goel V, Bhaduri S. A fast route to modify biopolymer surface: A study on polyetheretherketone (PEEK). Mater Lett 2014; 125: 96-98.

9. **Zhou H, Nabiyouni M, Bhaduri SB. Microwave assisted apatite coating deposition on Ti6Al4V implants. Mater Sci Eng C 2013; 33:4435-4443.

10. *Bigi A, Boanini E, Panzavolta S, Roveri N. Biomimetic growth of hydroxyapatite on gelatin films doped with sodium polyacrylate. Biomacromolecules 2000; 1:752-756.

11. Oyane O, Onuma K, Ito A, Kim HM, Kokubo et al. Formation and growth of clusters in conventional and kinds of simulated body fluids. J Biomed Mater Res A 2003; 64A:339.

12. Dorzhkina EI and Dorozhkin SV. Surface mineralization of hydroxyapatite in modified simulated body fluid with higher amounts of hydrogencarbonate ions. Coll. Surface. A 2002; 210:41-48.

13. Bayratkar D, Tas AC. Chemical preparation of carbonated calcium hydroxyapatite powders at $37^{\circ} \mathrm{C}$ in urea-containing synthetic body fluids. J Eur Ceram Soc. 1999; 19:2573-2579.

14. Tas AC. Synthesis of biomimetic Ca-hydroxyapatite powders at $37^{\circ} \mathrm{C}$ in synthetic body fluids. Biomaterials 2000; 21:1429-1438.

15. Kim H, Kishimoto K, Miyaji et al. Composition and structure of apatite formed on organic polymer in simulated body fluid with a high content of carbonate ion. $\mathbf{J}$ Mater Sci-Mater M 2000; 11:421-426.

16. Greish YE, Brown PW. Characterization of bioactive glass-reinforced HAP-polymer composites. J Biomed Mater Res A 2000; 52:687-694. 
17. Sun T, Wang M. Electrochemical deposition of apatite/collagen composite coating on NiTi shape memory alloy and coating properties. Mater Res Soc Symp Proc 2010; 1239:141-146.

18. Miyaji F, Kim HM, Handa S, Kokubo T, Nakamura T. Bonelike apatite coating on organic polymers: novel nucleation process using sodium silicate solution. Biomaterials 1999; 20:913-919.

19. Habibovic P, Barrère F, Van Blitterswijk CA, de Groot K, Layrolle P. Biomimetic Hydroxyapatite Coating on Metal Implants. J Am Ceram Soc 2002; 85:517-522.

20. Dorozhkina EI, Dorozhkin SV. Structure and properties of the precipitates formed from condensed solutions of the revised simulated body fluid. J Biomed Mater Res A 2003; 67A:578-581.

21. *Muller L, Muller FA. Preparation of SBF with different $\mathrm{HCO}_{3}^{-}$content and its influence on the composition of biomimetic apatites. Acta Biomater. 2006; 2:181-189.

22. Zhang Y, Venugopal J, Huang Z, Lim C, Ramakrishna S. Characterization of the surface biocompatibility of the electrospun PCL-collagen nanofibers using fibroblasts. Biomacromolecules. 2005; 6:2583-2589.

23. Yang F, Wolke J, Jansen J. Biomimetic calcium phosphate coating on electrospun poly (epsilon-caprolactone) scaffolds for bone tissue engineering. Chem Eng J 2008; 137:154-161.

24. Oyane A, Uchida M, Yokoyama Y, Choong C, Triffitt J, Ito A. Simple surface modification of poly(epsilon-caprolactone) to induce its apatite-forming ability. $\mathrm{J}$ Biomed Mater Res A 2005; 75A:138-145. 
25. *Arafat M, Lam C, Ekaputra A, Wong S, Li X, Gibson I. Biomimetic composite coating on rapid prototyped scaffolds for bone tissue engineering. Acta Biomater $2011 ; 7: 809-820$.

26. Araujo JV, Martins A, Leonor IB, Pinho ED. Surface controlled biomimetic coating of polycaprolactone nanofiber meshes to be used as bone extracellular matrix analogues. J. Biomater. Sci. Polymer Edn. 2008; 19:1261-1278.

27. Suarez-Gonzalez D, Barnhart K, Migneco F, Flanagan C, Hollister S, Murphy, W. Controllable mineral coatings on PCL scaffolds as carriers for growth factor release. Biomaterials 2012; 33, 713-721.

28. Huang R, Li W, Lv X, Lei Z, Bian Y, Deng H, Li X. Biomimetic LBL structured nanofibrous matrices assembled by chitosan/collagen for promoting wound healing. Biomaterials 2015; 53: 58-75.

29. Yang, X, Roach H, Clarke N, Howdle S, Quirk R, Shakesheff K, Oreffo R. Human osteoprogenitor growth and differentiation on synthetic biodegradable structures after surface modification. Bone 2011; 29: 523-531.

30. Kim S, Gwak S, Kim B. Orthotopic bone formation by implantation of apatite-coated poly(lactide-co-glycolide)/hydroxyapatite composite particulates and bone morphogenetic protein-2. J Biomed Mater Res A 2008; 87A: 245-253.

31. Son J, Kim S, Oh J, Appleford M, Oh S, Ong J, Lee K. Hydroxyapatite/polylactide biphasic combination scaffold loaded with dexamethasone for bone regeneration. J Biomed Mater Res A 2011; 99A: 638-647.

32. Luong L, McFalls K, Kohn D. Gene delivery via DNA incorporation within a biomimetic apatite coating. Biomaterials 2009; 30: 6996-7004. 
33. *Shi X, Fujie T, Saito A, Takeoka S, Hou Y, Shu Y, Khademhosseini A. PeriosteumMimetic Structures Made from Freestanding Microgrooved Nanosheets. Adv Mater 2014; 26: 3290-3296.

34. Yu S, Hariram K, Kumar R, Cheang P, Aik K. In vitro apatite formation and its growth kinetics on hydroxyapatite/polyetheretherketone biocomposites. Biomaterials 2006; 26: 2343-2352.

35. Chi M, Tsou H, Chung C, He J. Biomimetic hydroxyapatite grown on biomedical polymer coated with titanium dioxide interlayer to assist osteocompatible performance. Thin solid films 2013; 549: 98-102.

36. Zheng Y, Xiong C, Zhang, L. Formation of bone-like apatite on plasma-carboxylated poly(etheretherketone) surface. Mater Lett 2014; 126: 147-150.

37. *Kakinuma H, Ishii K, Ishihama H, Honda M, Toyama Y, Matsumoto M, Aizawa M. Antibacterial polyetheretherketone implants immobilized with silver ions based on chelate-bonding ability of inositol phosphate: Processing, material characterization, cytotoxicity, and antibacterial properties. Journal of Biomedical Sci 2015; 103: 57-64.

38. Habibovic P, Barrere F, van Blitterswijk C, de Groot K, Layrolle P. Biomimetic hydroxyapatite coating on metal impalnts. J Am Ceram Soc 2002; 85: 517-522.

39. Song W, Jun Y, Han Y, Hong S. Biomimetic apatite coatings on micro-arc oxidized titania. Biomaterials 2004; 25: 3341-3349.

40. Barrere F, van Blitterswijk C, de Groot K, Layrolle P. Influence of ionic strength and carbonate on the Ca-P coating formation from SBFx5 solution. Biomaterials 2002; 23: 1921-1930. 
41. Barrere F, van Blitterswijk C, de Groot K, Layrolle P. Nucleation of biomimetic Ca-P coatings on Ti6A14V from a SBF x 5 solution: influence of magnesium. Biomaterials 2002; 23: 2211-2220.

42. Barrere F, Layrolle P, Van Blitterswijk C, De Groot K. Biomimetic calcium phosphate coatings on Ti6Al4V: A crystal growth study of octacalcium phosphate and inhibition by $\mathrm{Mg}^{2+}$ and $\mathrm{HCO}^{3-}$. Bone 1999; 25: 107S-111S.

43. Liu Q, Ding J, Mante F, Wunder S, Baran G. (2002, August). The role of surface fucntional groups in calcium phosphate nucleation on titanium foil: a self-assembled monolayer technique. Biomaterials 2002; 23: 3103-3111.

44. Ma J, Wong H, Kong L, Peng K. Biomimetic processing of nanocrystallite bioactive apatite coating on titanium. Nanotechnology 2003; 14: 619-623.

45. Kodama A, Bauer S, Komatsu A, Asoh H, Ono S, Schmuki P. Bioactivation of titanium surfaces using coatings of $\mathrm{TiO}_{2}$ nanotubes rapidly pre-loaded with synthetic hydroxyapatite. Acta Biomater 2009; 5: 2322-2330.

46. Oliveira A, Malafaya, Reis R. Sodium silicate gel as a precursor for the in vitro nucleation and growth of a bone-like apatite coating in compact and porous polymeric structures. Biomaterials 2003; 24: 2575-2584.

47. Forsgren J, Svahn F, Jarmar T, Engqvist H. Formation and adhesion of biomimetic hydroxyapatite deposited on titanium substrates. Acta Biomater 2007; 3: 980-984.

48. Staiger MP, Pietak AM, Huadmai J, Dias G. Magnesium and its alloys as orthopedic biomaterials: A review. Biomaterials 2006; 27:1728-1734. 
49. Witte F, Kaese V, Haferkamp H, Switzer E, Meyer-Lindenberg A, Wirth C, Windhagen $\mathrm{H}$. In vivo corrosion of four magnesium alloys and the associated bone response. Biomaterials 2005; 26:3557-3563.

50. Li L, Gao J, Wang Y. Evaluation of cyto-toxicity and corrosion behavior of alkaliheat-treated. Surf Coat Tech 2004; 185:92-98.

51. Gray-Munro JE, Seguin C, Strong M. Influence of surface modification on the in vitro corrosion rate of magnesium alloy AZ31. J Biomed Mater Res A 2009; 91A:221-230.

52. Keim S, Brunner JG, Fabry B, Virtanen S. Control of magnesium corrosion and biocompatibility with biomimetic coatings. J Biomed Mater Res B 2011; 96B:84-90.

53. Zhang Y, Zhang G, Wei M. Controlling the biodegradation rate of magnesium using biomimetic apatite coating. J Biomed Mater Res B 2009; 89B:408-414.

54. Cui FZ, Yang JX, Jiao YP, Yin QS, Zhang Y, Lee IS. Calcium phosphate coating on magnesium alloy for modification of degradation behavior. Frontiers of Materials Science in China 2008; 2:143-148.

** indicates papers of outstanding interest; * indicates papers of special interest. 


\section{Figure captions}

Figure 1(a): Number of publications using "Biomemetic Coating simulated Body Fluid" as the key phrase (2000-2015). Data base: Web of Science.

Figure 1(b): Number of citations using "Biomemetic Coating simulated Body Fluid" as the key phrase (2001-2016). Data base: Web of Science.

Figure 2: Comparison between the conventional and microwave assisted processes [9]. Note the difference in the final stage 5(a) and 5(b). The former represents the conventional process and the later represents the microwave assisted process. Also note thicker coating in 5(a) as opposed to thinner coating in the $5(\mathrm{~b})$. 


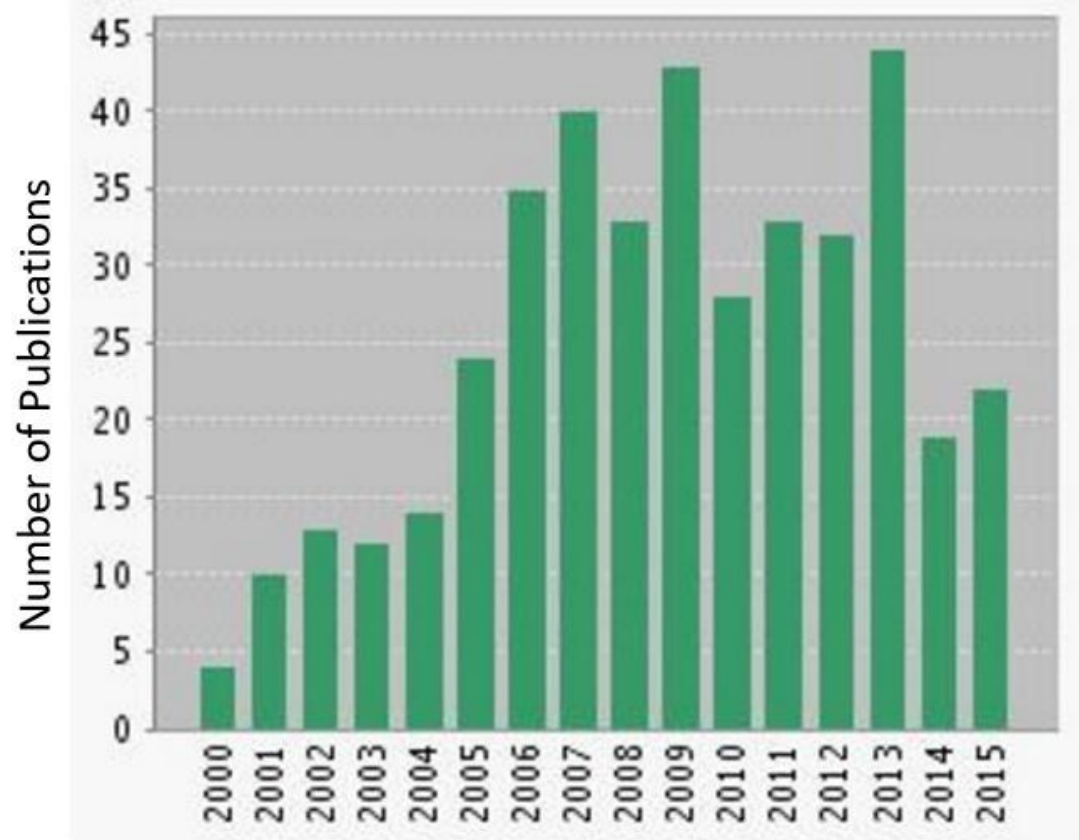

Year

Figure 1(a)

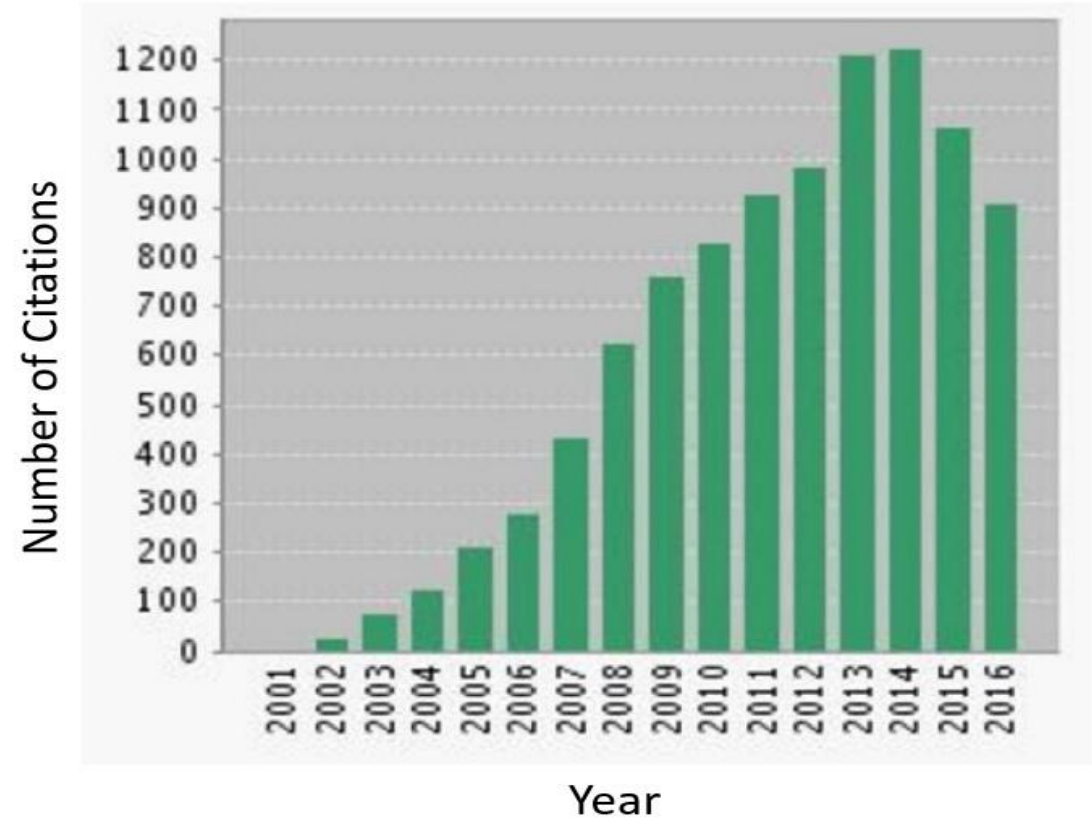

Figure 1(b) 


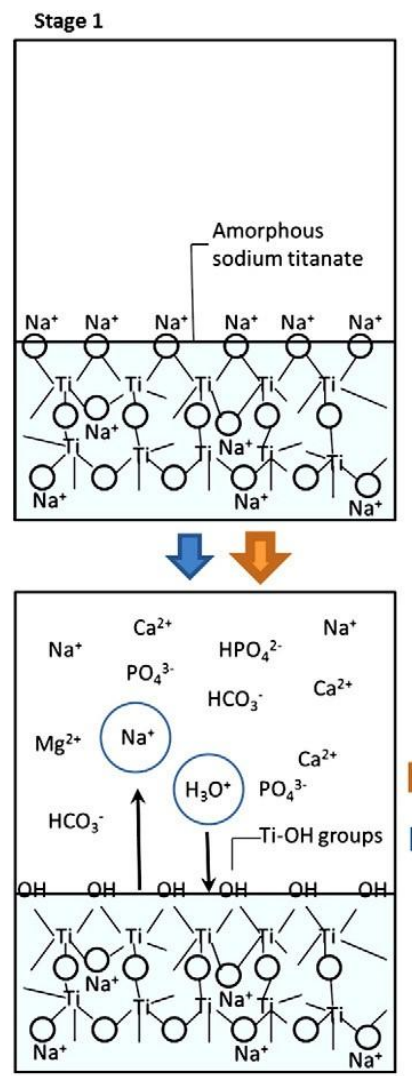

Stage 2
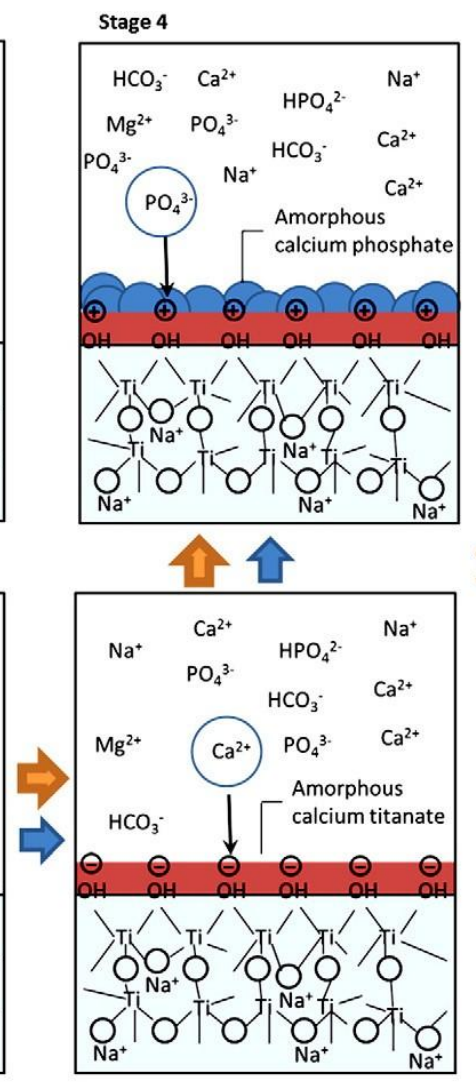

Stage 3

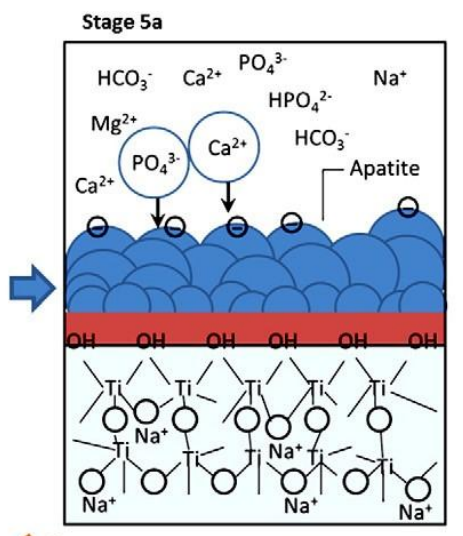

$M$

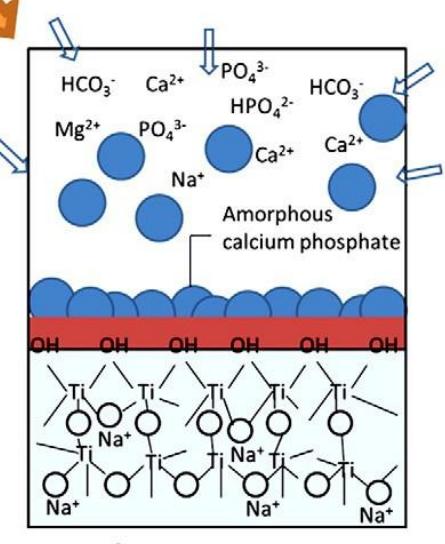

Stage 5b

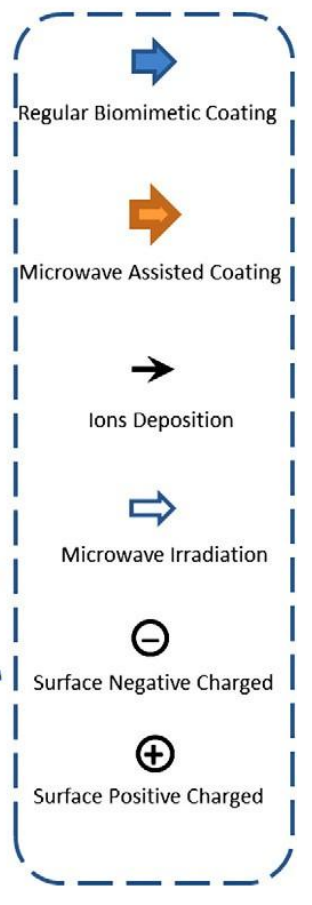

Figure 2 
Table 1: Ion Concentrations of Human Plasma and Various SBFs, mM

\begin{tabular}{|l|l|l|l|l|l|l|l|l|l|}
\hline & $\begin{array}{l}\text { Blood } \\
\text { Plasma }\end{array}$ & Ringer & EBSS & HBSS & $\begin{array}{l}c- \\
\text { SBF }\end{array}$ & $\begin{array}{l}\text { Tas- } \\
\text { SBF }\end{array}$ & $\begin{array}{l}\text { Bigi- } \\
\text { SBF }\end{array}$ & $r$-SBF & Muller- \\
\hline $\mathrm{Na}^{+}$ & 142.0 & 130.0 & 143.5 & 142.1 & 142.0 & 142.0 & 141.5 & 142.0 & 142.0 \\
\hline $\mathrm{K}^{+}$ & 5.0 & 4.0 & 5.37 & 5.33 & 5.0 & 5.0 & 5.0 & 5.0 & 6.5 \\
\hline $\mathrm{Ca}^{2+}$ & 2.5 & 1.4 & 1.8 & 1.26 & 2.5 & 2.5 & 2.5 & 2.5 & 2.5 \\
\hline $\mathrm{Mg}^{2+}$ & 1.5 & & 0.8 & 0.9 & 1.5 & 1.5 & 1.5 & 1.5 & 1.5 \\
\hline $\mathrm{Cl}^{-}$ & 103.0 & 109.0 & 123.5 & 146.8 & 147.8 & 125.0 & 124.5 & 103.0 & 148.0 \\
\hline $\mathrm{HCO}_{3}{ }^{-}$ & 27.0 & & 26.2 & 4.2 & 4.2 & 27.0 & 27.0 & 27.0 & 4.2 \\
\hline $\mathrm{HPO}_{4}{ }^{2-}$ & 1.0 & & 1.0 & 0.78 & 1.0 & 1.0 & 1.0 & 1.0 & 1.0 \\
\hline $\mathrm{SO}_{4}{ }^{2-}$ & 0.5 & & 0.8 & 0.41 & 0.5 & 0.5 & 0.5 & 0.5 & 1.0 \\
\hline $\mathrm{Ca}^{\mathrm{P}}$ & 2.5 & & 1.8 & 1.62 & 2.5 & 2.5 & 2.5 & 2.5 & 2.5 \\
\hline $\mathrm{Buffer}^{2}$ & & & & & Tris & Tris & Hepes & Hepes & Tris \\
\hline $\mathrm{pH}^{2}$ & 7.4 & 6.5 & $7.2-7.6$ & $6.7-6.9$ & 7.4 & 7.4 & 7.4 & 7.4 & $7.3-7.4$ \\
\hline
\end{tabular}


Table-2. Important examples of biomimetic coatings on polymeric substrates

\begin{tabular}{|c|c|c|}
\hline $\begin{array}{l}\text { Serial } \\
\text { No. }\end{array}$ & Authors & Significant Outcomes \\
\hline 1. & $\begin{array}{l}\text { Biodegradable Polymer Substrates: } \\
\text { A. Poly(c-caprolacetone) (PCL) }\end{array}$ & \\
\hline & i. Zhang et al. [22] & $\begin{array}{l}\text { Bone marrow stromal cells infiltrate up to } 48 \\
\text { and } 114 \mu \mathrm{m} \text { into electrospun PCL and } \\
\text { PCL/gelatin scaffold respectively. }\end{array}$ \\
\hline & ii. $\quad$ Yang et al. [23] & $\begin{array}{l}>\text { Uniform fiber coating with higher scaffold } \\
\text { surface density than in center was produced. } \\
>\text { After } 7 \text { days SBF immersion, calcium } \\
\text { deficient coating was recorded. }\end{array}$ \\
\hline & iii. $\quad$ Oyane et al. [24] & $\begin{array}{l}\text { Dense, uniform, thin and irremovable layer } \\
\text { of interconnected porous apatite structure } \\
\text { formed over 2D and 3D structures. }\end{array}$ \\
\hline & iv. Arafat et al. [25] & $\begin{array}{l}\text { Higher compressive modulus, excellent } \\
\text { adhesive property, enhanced BMSCs } \\
\text { formation observed on CHA/gelatin-coated } \\
\text { scaffolds. }\end{array}$ \\
\hline
\end{tabular}




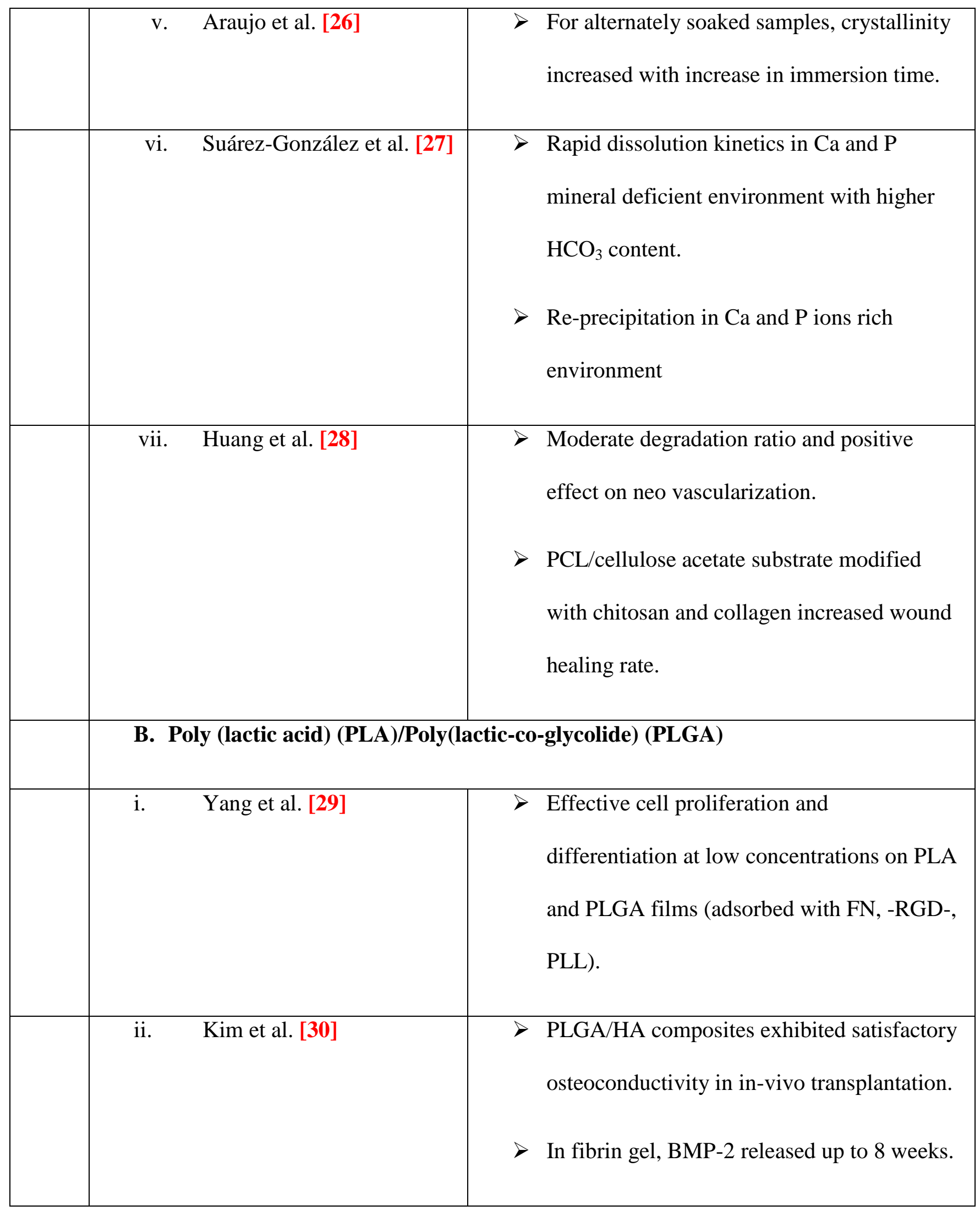




\begin{tabular}{|c|c|c|c|c|}
\hline & & Son et al. [31] & & $\begin{array}{l}\text { Daily dose release of less than 100ng of } \\
\text { dexamethasone (DEX) in vitro through } \\
\text { porous HA/DEX-loaded PLA biphasic } \\
\text { scaffold. }\end{array}$ \\
\hline & & Luong et al. [32] & $>$ & $\begin{array}{l}\text { Better cellular uptake, homogenous DNA- } \\
\text { Lipoplex protein distribution on } \\
\text { organic/inorganic hybrid. } \\
\text { Highest transfection efficiency for } 6 \mathrm{~h} \text { of } \\
\text { coprecipitation }\end{array}$ \\
\hline & & Shi et al. [33] & $>$ & $\begin{array}{l}\text { Direct cellular alignment, protein and gene } \\
\text { expression observed when micropatterning } \\
\text { was done PLGA nanosheets. }\end{array}$ \\
\hline 2. & \multicolumn{4}{|c|}{ Non-biodegradable Polymer Substrate: Polyetherether ketone (PEEK) } \\
\hline & i. & Yu et al. [34] & $>$ & $\begin{array}{l}\text { Crystal quantity was proportional to the HA } \\
\text { volume fraction, in HA/PEEK composite } \\
\text { Crystal size increased with prolonged } \\
\text { immersion time and HA volume fraction. }\end{array}$ \\
\hline & & Chi et al. [35] & $>$ & $\begin{array}{l}\text { AIP technique resulted in columnar and } \\
\text { crystalline anatase or rutile phase for } \mathrm{R}-\mathrm{TiO}_{2} \\
\text { /PEEK specimens } \\
\text { Superior HA formation and }\end{array}$ \\
\hline
\end{tabular}




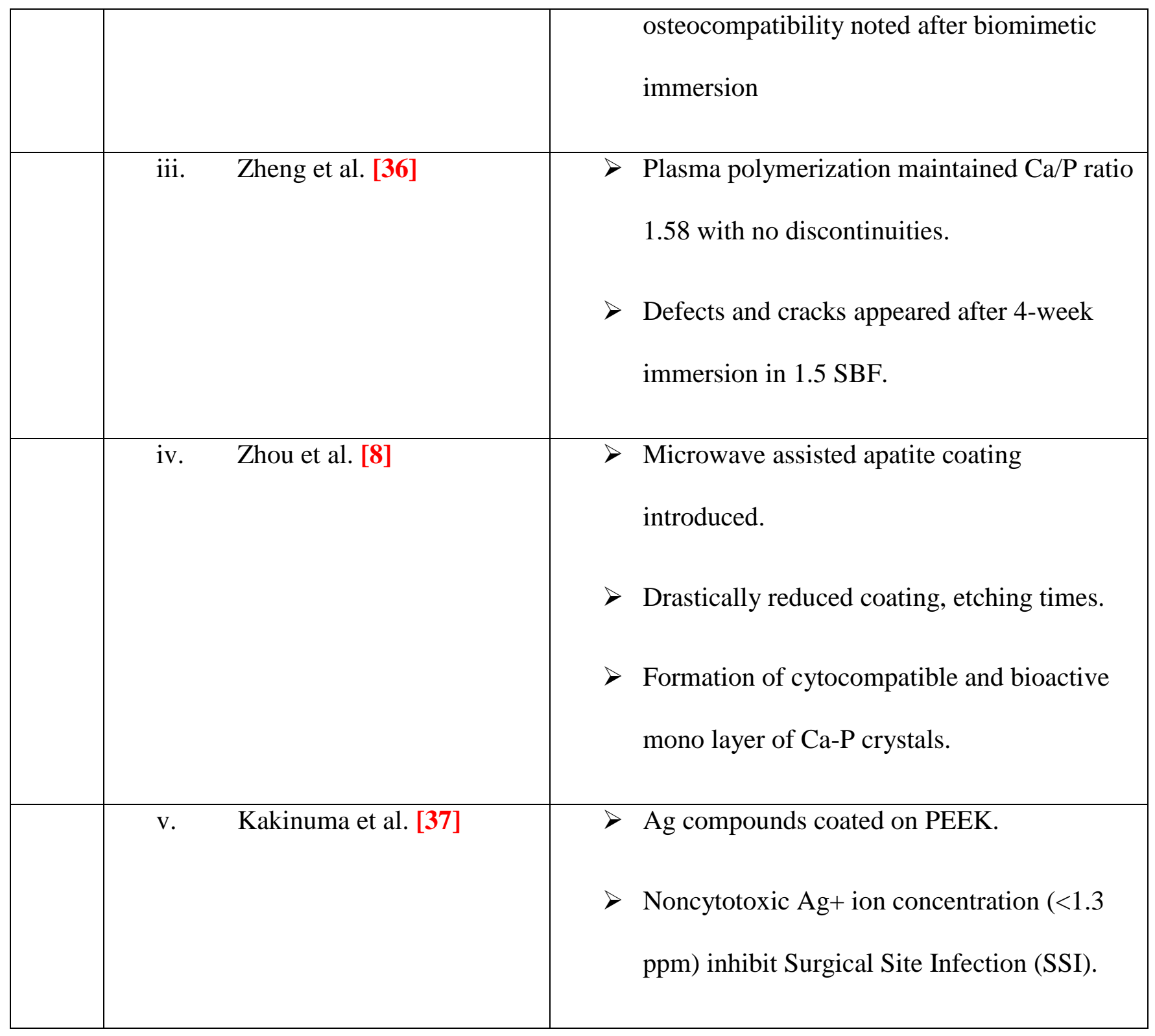


Table-3. Important examples of biomimetic coatings on metallic substrates

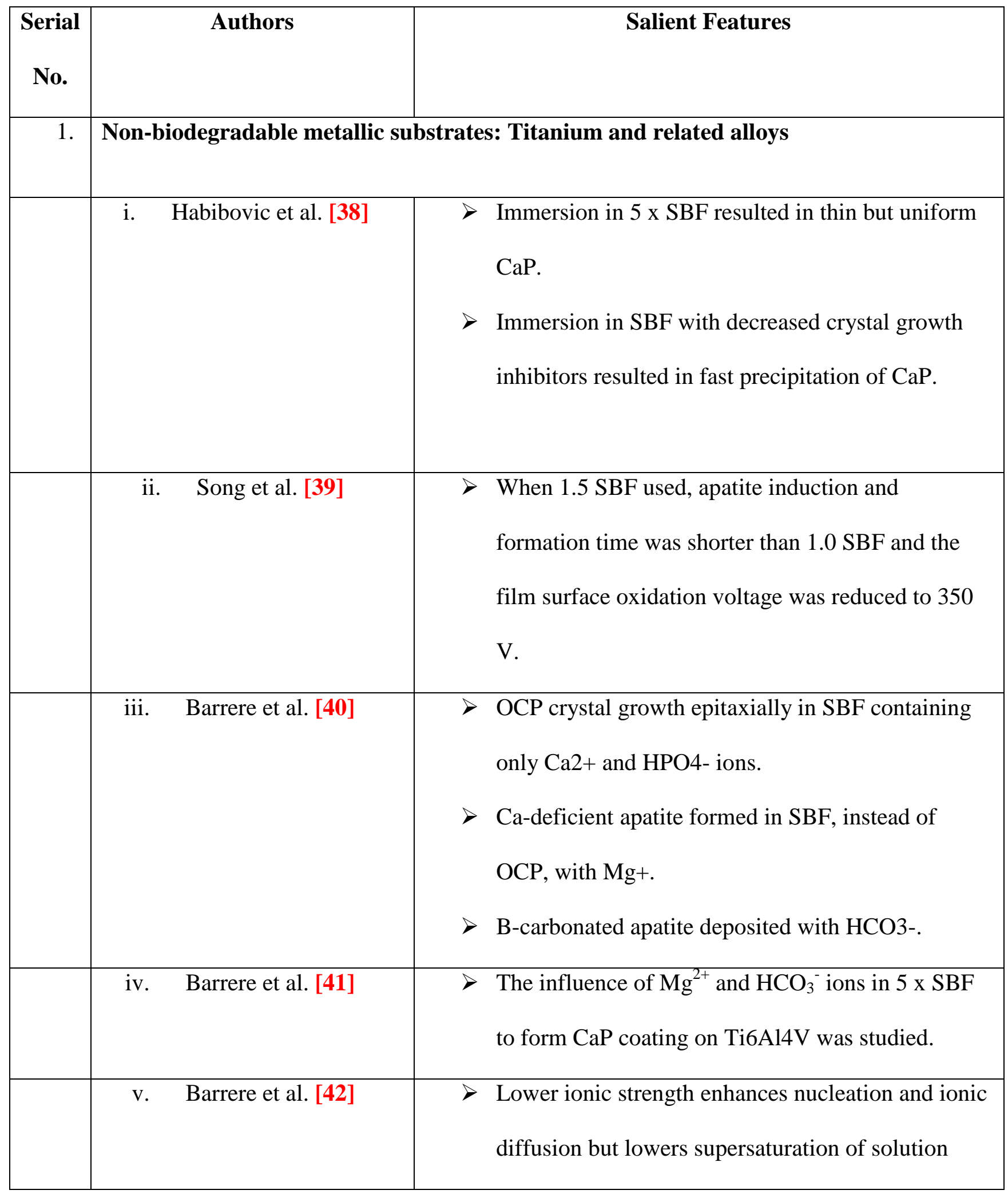




\begin{tabular}{|c|c|c|}
\hline & & $\begin{array}{l}\text { accounting for detrimental effect in coating } \\
\text { formation }\end{array}$ \\
\hline vi. Liu et al. [43] & $>$ & $\begin{array}{l}\text { Rapid CaP induction in } 1.5 \mathrm{SBF} \text { within } 18 \text { hours } \\
\text { regardless of the amount of pre-deposited HA. }\end{array}$ \\
\hline vii. $\quad$ Tas et al. [7] & $>$ & $\begin{array}{l}65 \mu \mathrm{m} \text { apatitic calcium phosphate coating was } \\
\text { prepared using } 10 \times \mathrm{SBF} \text { solution. } \\
\text { This coating process presents the linear and fast } \\
\text { deposition kinetics. }\end{array}$ \\
\hline $\begin{array}{ll}\text { viii. } & \text { Ma et al. [44] }\end{array}$ & $>$ & $\begin{array}{l}\text { Uniform layer of apatite with nanocrystalline } \\
\text { microporous structure formed. } \\
\text { Apatite thickness saturation in } 1.5 \mathrm{SBF} \text { after } 10 \\
\text { days; }\end{array}$ \\
\hline ix. Kodama et al. [45] & $>$ & $\begin{array}{l}\text { Massive acceleration of apatite deposition rate } \\
\text { (upto } 20 \text { folds) for alternative immersion method } \\
\text { treated } \mathrm{TiO}_{2} \text { nanotubes, when immersed in } 10 \mathrm{x} \\
\mathrm{SBF} \text {. }\end{array}$ \\
\hline $\begin{array}{ll}\text { x. } & \text { Oliveira et al. [46] }\end{array}$ & $D$ & $\begin{array}{l}\text { Sodium silicate gel as precursor followed by SBF } \\
\text { immersion resulted in apatite formation after } 6 \\
\text { hours. }\end{array}$ \\
\hline xi. $\quad$ Forsgren et al. [47] & $>$ & $\begin{array}{l}\text { Immersion in PBS instead of SBF resulted in } \\
\text { forming similar HA layer, several micrometers } \\
\text { thick, after } 7 \text { days. }\end{array}$ \\
\hline
\end{tabular}




\begin{tabular}{|c|c|c|}
\hline & xii. $\quad$ Zhou et al. [9] & $\begin{array}{l}\text { Microwave energy significantly promotes the } \\
\text { deposition kinetics of apatite. } \\
\text { Microwave assisted coating process has the great } \\
\text { potential to be employed as the rapid surface } \\
\text { modification of biomaterials. }\end{array}$ \\
\hline \multirow[t]{4}{*}{2.} & \multicolumn{2}{|c|}{ Biodegradable Metallic substrates: Magnesium and related alloys } \\
\hline & i. Witte et al. [49] & $\begin{array}{l}\text { Bone cell activation in high } \mathrm{Mg} \text { ion concentration. } \\
\text { surrounding soft tissue. } \\
>\text { Gowever, no bone formation was found in } \\
\text { but no adverse effects was recorded. }\end{array}$ \\
\hline & ii. Li et al. [50] & $\begin{array}{l}99.99 \% \text { pure magnesium, alkali and heat treated, } \\
\text { exhibited no mass loss when immersed in SBF } \\
\text { (high and low concentration of } \mathrm{Cl}^{-} \text {ions) for } 180 \\
\text { days. } \\
\text { While marrow cell growth was not affected, apatite } \\
\text { coating hindered corrosion of } \mathrm{Mg} \text { substrates. }\end{array}$ \\
\hline & iii. Gray-Munro et al. [51] & $\begin{array}{l}\text { Surface modification minimizes production of toxic } \\
\text { by-products. } \\
>\text { Corrosion rate of surface treated } \mathrm{Mg} \text { alloys in }\end{array}$ \\
\hline
\end{tabular}




\begin{tabular}{|c|c|c|}
\hline & & $\begin{array}{l}\text { descending order: } \\
\text { Clean > Acid Etched > Calcium Phosphate Coated } \\
>\text { PLA Coated > Poly(DTH carbonate) Coated }\end{array}$ \\
\hline iv. Keim et al. [52] & $>$ & $\begin{array}{l}\text { Spontaneous biomimetic layer, containing } \mathrm{Ca}, \mathrm{P} \\
\text { and } \mathrm{C} \text {, was formed in cell culture medium. } \\
\text { This reduced } \mathrm{Mg} \text { release by } 60 \% \text { coupled with } \\
\text { enhanced cell adhesion. }\end{array}$ \\
\hline v. Zhang et al. [53] & $>$ & $\begin{array}{l}\text { Thickness of apatite coating, formed by SBF } \\
\text { immersion, determines the corrosion rate of } \mathrm{Mg} \\
\text { substrate. }\end{array}$ \\
\hline vi. Cui et al. [54] & $>$ & $\begin{array}{l}\text { Formation of non-uniform and porous CaP coatings } \\
\text { with a significant reduction in degradation rate of } \\
\text { Mg alloy substrates. }\end{array}$ \\
\hline
\end{tabular}

